\title{
Comparative Study of Functions Affecting the Behavioral Patterns of Tourists in Iran and America's Tourism Marketing Plan Utilizing SWOT Model
}

\author{
Issa Ebrahimzadeh, Monir Yari \\ Faculty of Geography and Environmental Planning, University of Sistan and Baluchestan, Zahedan, Iran. \\ Email: M_A_Daraei@yahoo.com
}

Received November $14^{\text {th }}, 2012$; revised December $16^{\text {th }}$, 2012; accepted December $30^{\text {th }}, 2012$

\begin{abstract}
Behavioral patterns of tourists are designed aiming to present a scientific framework of how the variables are interacted and factors influencing consumer behavior can help decision makers and market activists in predicting and controlling consumer behavior. This study aims to explore the functions influencing tourist's behavioral patterns in Iran and America's tourism marketing planning which has comparatively been studied. The research methodology is analytical-descriptive and it has been studied and analyzed utilizing SWOT technique. Analytical results of this study show that America in proportion with culture, potentials and operational functions in Iran can be in some cases exploited.
\end{abstract}

Keywords: Tourism; Tourists Behavioral Patterns; Marketing; SWOT Technique; Iran; America

\section{Introduction}

Tourism development, particularly for developing countries to get away from problems such as high unemployment, limited foreign exchange and single-product economy is very important. Iran's economy which is highly dependent on the incomes obtained from oil exchange, its macro-economic variables are affected to strong fluctuations over time, in order to diversify sources of economic growth and foreign exchange earnings as well as creating new job opportunities in the country, tourism development is highly important in [1].

The researches performed by World Tourism Organization and other ones show that marketing is essential for developing this industry in any country or region' however, people must be known the tourism potentials of that specific region to attract tourists to a region [2]. However, the point is that the majority of tourists attractions in Iran are not only are not well known not only in Iran, but in abroad. Therefore, it seems that marketing weaknesses and lack of appropriate advertising with tourist's needs and tourism markets and also lack of designing tourists' behavioral patterns is one of the factors that can be associated with Iran's underdevelopment tourism industry. Although the studies indicate that only marketing cannot be led to sustainable development of tourism industry for the attractions of a region without existing infrastructure facilities and services, the necessity and significance of marketing planning is to the extent that it is sometimes considered in the field of tourism literature as a main pillar of developing this industry in tourism plans. Therefore, designing and developing macroeconomics and also strategic approaches for tourism development in the framework of "tourism marketing planning process" is so critical [3].

\section{Research Theoretical Approach}

\subsection{Tourist's Behavioral Patterns}

Behavioral, conceptual and motivational differences have great impact on personal decisions; individuals' behavior depends on their conception of the world and is influenced by their subjective perception toward a location or a travel agency which are determined by factors such as childhood, family experiences and working personality. Tourism factors include supply and demand and the study of tourist's behavior is taken into account the supply dimension, as most researchers focused their attention to research attractions (supply). It is essential that tourism enterprises identify their demographic and geographical characteristics of their consumers [4]. Tourism behavioral studies will be taken shape in three categories namely before travel, during travel and after travel.

- Before the travel category includes the study of complex affecting issues on travel decision making and the intention to visit a tourist destination. For example, the destination image is influenced by people's fea- 
tures, psychology, previous experiences and motivation.

- By during the travel, it means the tourist behavior and their perception of the quality of facilities and the amount of money they spent.

- After the travel includes satisfaction and fulfillment of tourists and the intention to return again as well as the tourist's reception with the host community.

Tourists behaviors (Figure 1) includes human's reaction against needs and their demands to decide to have a travel, then the satisfaction or dissatisfaction of tourists with tourist facilities, services and attractions during travel and ultimately their understanding of tourism destinations, persistency, the decision to return or not to return to the tourist destination and travel reflection. Meanwhile, tourist's behavioral patterns consist of categorizing the tourists in similar and convergent groups based on their behavior in three stages of before the travel, during the travel and after the travel [5].

\subsection{Market and Tourism Marketing}

Market is a set of actual and potential purchasers of a product; a potential market is the customers that have the desire and interest to buy goods or services. In order to potential customers become actual customers, they should both have access to product and have enough income. Therefore, an accessible market is the set of customers who have the interest and power to buy products and have access to the regarded product. The concept of market finally brings us to the concept of marketing. Marketing means working with markets to provide ex-

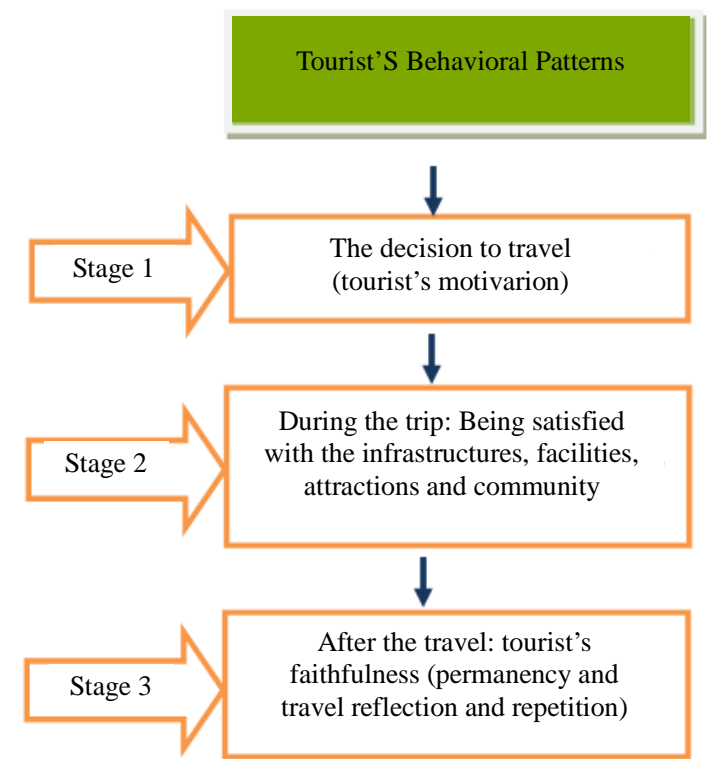

Figure 1. Tourist's behavioral patterns in three stages of decision to travel, during the travel and after the travel [5]. changes with the aim of supplying human's needs and desires [6]. Meanwhile, the concept of marketing can be defined in a simple term; that is coordinating the product with the needs and demands of the market and people and what they want to buy should be offered and suggested [7]. Marketing services is certainly complex, for they do not have the capability to store and stock services and for this respect its marketing differs from marketing products and its supplying method to markets is also different [8].

Marketing is necessary and essential for sustaining the existence of tourism industry. In fact, the potential tourists can be attracted to the purposes intended for through marketing methods. Therefore, developing strategic marketing programs can effectively contribute in achieving the objectives of tourism projects [3]. Despite the fact that marketing discussions are extensive, its position in tourism industry management and development is essential [9]. In fact, market segmentation is a process of identifying major differences in the characteristics of the buyer to divide the market into two or more groups with a specific goal, selecting the part of the market that the institution will serve with and also designing the product and marketing programs in such a way that it satisfies the specific features of the targeted group [10]. Tourism marketing aims to identify and predict the tourist's needs and providing facilities to meet their needs and making them informed and creating motivation within them to visit the destination again [11]. Given the specific characteristics of tourism products, the role of marketing in this industry has particular importance than other industries and effective use of tourism marketing tools is essential for a country or region, for the potential tourists can be supplied with information about what a specific region can provide through marketing and encourage them to visit that region [12].

\section{Examples of Comprehensive Behavioral Patterns of Tourists in America}

Tourist's behavioral pattern and American's lifestyle: Stanford Research Institute devised an improved method for America's market segmentation which is called VALS2, which is based on the concept of self-justification and customer-provided resources, and its justification is based on how customers search for and provide goods and services; those which satisfy them and show their personal identity. Therefore, they are prone to purchase influenced by the principles, conditions and their actions [13]. Its most significant segmentation is called VALS2 which stands for Values and Lifestyle which people within are divided into 8 groups based on how they spend their time and money as follows: 
- Self-flourishing or self-discovery: customers who have high income and are successful, active, modern and responsible. These customers are looking for the best products.

- Prosperous: mature professional and responsible customers who have higher education, and their information about global issues is good and are ready to accept new ideas and social changes. They prefer products which are durable and have appropriate performance and value.

- Successful: people who are successful and professional who obtain their satisfaction from their family and business. They are looking for products that provide them prestige which indicates their success.

- Experience-driven: these consumers are young people with 25 years mean age; they have lots of energy spent for exercise and social activities. A large part of their income is spent on clothing, food, music, cinema and other new products with an emphasis on being modern.

- Believers: they are conservative and traditional people which welcome familiar and well-accustomed products as well as are middle-income.

- Hard-working: people with low financial resources and feeling of insecurity who are seeking for other's approval. These customers are looking for buying fashionable products to show themselves as those who have high financial resources.

- Constructive: they are pragmatic, self-sufficient-traditional and family-oriented people. Their income is low and they are seeking for products that can be applied.

- Activist: these consumers are in the lowest income levels. They are elderly, retired and passive people; their average age is 61 years old and they are loyal to their favorite brands [6].

Motivational Behavioral Pattern of American Tour-

ists: Maslow presented for the first time the pyramid of human needs with psychological and human motivation approach in his valuable works entitled "Motivation and Personality" in 1954 (Figure 2) which has taken into consideration a pattern of human behaviors. In fact, Maslow maintains that it is possible that human motivations and behaviors in the field of tourism suggest his/her needs. These needs are often manifested behind human's activities and personal or hidden matters [14].

The above-mentioned theory contributes the consumption behavior in tourism industry [15]. Also, the differences and its influences in tourist's behaviors and relationships with physical and cultural milieus as well as people during travel and in destination has caused that the categories are useful in such a way that it offers a

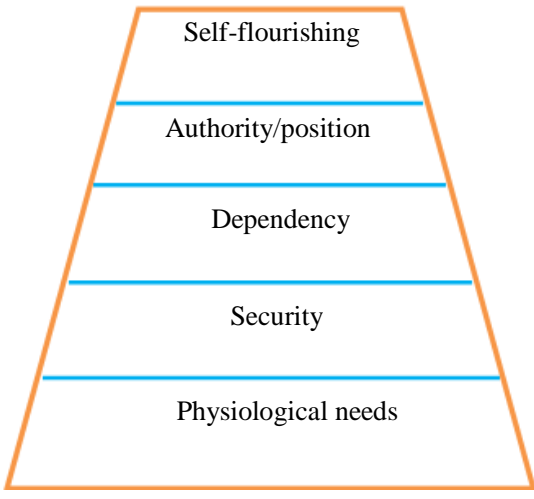

Figure 2. Hierarchy of needs according to Maslow's ideas (1954).

simple classification of complex phenomena, allowing them to be understood. Much of this work was done during the 1970s and early 1980s and part of it was reviewed by Lowick and Fen Rongeno and Blaert (1992). The especially began discussion about Gallup Organization which was representative of American Express Travel Services. The aim of the above study was traveller's classification and by making initial talks from 6500 volunteers' respondents in United States, Germany, Great Britain and Japan, the world's four major economic forces, almost 4000 people were among the travellers from the total of respondents. The evaluation in overall showed that almost 13,000 people have been traveling over the past 12 months. According to this study, the tourists who decided to travel in different ways regardless of origin and destination have been divided into five groups as follows:

- Adventurers: they are independent and reckless and trying to create new activities, see new people and also become familiar with different cultures. They are generally more educated and more affluent than members of other groups. Travelling has a man role in life for these people. On the other hand, adventurers are young men who $44 \%$ of the members of the group are in the age range of 11 - 34 years old.

- Heartsick: these people are affected by too much worries and concerns and do not have confidence in decisions related to travelling and are generally scared of flying. These people are less educated and affluent than others. This group travel less than other four groups and if they initiate to have a travel, they will tend to domestic travels. Most of these people are women and a major part of them are elderly and nearly more than half of them have 50 years old.

- Whimsical people: these people are living with travelling imagination and supposition and hence they give importance for travelling during life. Despite many studies and discussions they made about new 
routes and destinations, their business travel is much less impressive than their thoughts and beliefs and often they have a tendency to rest relaxation than adventure and seeking for incidence. Such people can be among low income and less educated people who most of them are 50 year women or older than it. When these people travel to new places, they often carry maps and guide books with themselves.

- Thrifty people: travelling provides an opportunity for relaxation and leisure for thrifty people and it is an experience from the perspective of travelling that gives meaning to their life. Travelling costs does not matter for them and do not think of the notion that they should pay extra money for the services and facilities provided for. Such people have a moderate income and have not culturally been advanced. It can be said that they travel twice a year; even they do not have the ability to do so. These people are more women than men and are usually a little older than their travelling companions.

- Indulgent and wasteful people: the financial condition of such people is usually much better than other travellers and they want to pay more money for more convenience and better services during the travel. They tend to stay in great hotels compared to others and are more interested in indolence. They support the adventurers during travelling and the number of men and women in such group is the same [3].

\section{Examples of Comprehensive Behavioral Patterns of Tourists in Iran}

In order to achieve a comprehensive and sustainable development as well as replace alternative resources of revenue instead of oil resources in today Iran, using all the facilities and capabilities in our country are needed. In this regard, developing the tourism industry believed to the third dynamic and growing economic phenomenon after oil and automobile industry in the world by the economists is also considered as a basic requirement in Iran. Hence, reviewing the obstacles in the development of this industry in our country is very necessary. In this regard, the tourism marketing weaknesses can be one of the obstacles to tourism development in Iran. Meanwhile, the lack of conducting basic and applied research in the behavioral patterns of Iranian tourists as a prerequisite for tourism marketing is considered the most constraints of tourism development in Iran. Little research has been done in recent years in this field in a sporadic fashion as follows: in the study conducted by Ranjbarian \& Zahedi [16], the effects of repeated travels to Isfahan on the foreign tourist's satisfaction were explored and the results of their study indicate that the satisfaction level of tour- ists who repeat the travel to Isfahan was much lower than those who experience such a travelling for the first time. In the study performed by Kazemi M. [17], Zahedan citizen's understanding on Chabahar tourism development had has been analyzed. His findings indicate that inasmuch as product marketing of tourism in any country or region depends on buyer's interests and perceptions and with regard to the comprehensive tourism plan of Sistan and Baluchestan, Iran in intra-provisional tourism development strategy, now the motivation of Zahedan citizens to travelling to Chabahar are cultural, commercial, physical activities, gaining peace, natural, luxurious and emotional motivations. Reza Jaravandi \& Forghani [18] conducted a study entitled "comparison of travel motives among both youths and adults (a case study of Shiraz travellers and came to this conclusion that there is no significant difference between different age groups in travelling to Dubai. His studied motivation were divided into five groups among which the impact of age and life cycle are considered less effective and he maintained that its cause is to how advertise in that he represents travelling to Dubai as a trip to the whole family and no distinction is considered in age or gender in advertising, as the motivation all family members are more influenced by family and familial conditions than influenced by variables as cultural sub-groups or reference groups. Alilou et al. [19] compared in another study the personality traits of a group of Iranian tourists with a non-tourist group. The findings of this study showed that there is a significance difference between tourists and non-tourists in seeking emotion, extraversion and openness against experience. The tourist group achieved higher scores than the non-tourist ones in personality traits of extraversion, openness against experience. The extroverts are gregarious and plebiscites who prefer large groups and gatherings; as a result the extroverts are more willing to travel.

\section{Research Methodology}

Research methodology in this study is analytical-descriptive which describes and quantitatively and qualitatively analyze behavioral patterns and influential functions upon it in the tourism market section and the necessity of its development as the main pillar of developing this industry in tourism goals are studied. To collect required information and data, documentary and library studies have been used and the behavioral patterns in the two countries of Iran and America were analyzed. Then SWOT model was used to analyze findings and finally guidelines and strategies appropriate to developing influencing behavioral patterns as one if the pillars of marketing in Iran and America have been presented. The 
analysis of affecting factors facing tourism marketing using the gradation factors (Tables 1-4) [20].

\section{Research Locational Scope}

According to research purposes, which comparatively study the influential functions on tourist's behavioral patterns in the two developed and developing countries, the research locational scope has been selected in both Iran and America (Figure 3). United States of America as an area of 9,363,364 square kilometers is located in
North American continent. This country gained independence from England on 4/7/1776. The government type id federal republic with two legislative houses. English is the official language of this country and its capital is Washington, and the Islamic Republic of Iran as an area of 1,648,195 square kilometers is located in Asia. Iran has an ancient history and its government type is Islamic republic with one legislative house. Persian is the official language of this country and its capital is Tehran [21].

Table 1. Results of external factors analysis affecting marketing tourism of America.

\begin{tabular}{|c|c|c|c|}
\hline External environment (threats and opportunities) & weight & Grade & Weighted score \\
\hline O1—creating a balance between tourism firms, tourists and society's advantages & 0.01 & 3 & 0.03 \\
\hline O2_estimating the tourism markets opportunities & 0.04 & 2 & 0.08 \\
\hline O3_-government's support against competitors & 0.07 & 5 & 0.35 \\
\hline $\begin{array}{l}\text { O4-the growing process of America's tourism destination acceptance } \\
\text { through domestic and foreign markets }\end{array}$ & 0.04 & 4 & 0.14 \\
\hline O5-clear goals and proper planning of firms to achieve the objectives & 0.03 & 4 & 0.12 \\
\hline O6-the possibility of competition in international tourism markets & 0.05 & 4 & 0.20 \\
\hline O7—creating new ideas in marketing & 0.03 & 1 & 0.03 \\
\hline O8-tourism development as one of the factors of economic growth & 0.05 & 4 & 0.20 \\
\hline O9—developing promoting activities in the field of advertising & 0.05 & 1 & 0.05 \\
\hline O10-identifying strengths and weaknesses of one's own firms and those of competitors & 0.03 & 3 & 0.09 \\
\hline O11—formulaing the costs & 0.02 & 2 & 0.04 \\
\hline O12-increasing the country's exchange incomes & 0.08 & 4 & 0.32 \\
\hline O13_advertising in order to expand the use of country's aviation services & 0.04 & 4 & 0.16 \\
\hline O14—creating motives in potential tourists to travel to America & 0.04 & 3 & 0.12 \\
\hline \multicolumn{4}{|l|}{ O15_-gaining loyal customers in domestic and foreign markets } \\
\hline T1—tourism system leads strongly people towards dependence to materials & 0.01 & 2 & 0.02 \\
\hline T2-water pollution (people are invaded by advertising) & 0.01 & 2 & 0.02 \\
\hline T3—dividing the tourism markets into smaller sectors with less profitability & 0.05 & 3 & 0.15 \\
\hline T4-lack of ability to implement all strategies through tourism organization & 0.03 & 1 & 0.03 \\
\hline T5-taking into consideration general solutions in tourism markets & 0.04 & 3 & 0.12 \\
\hline T6-global markets segmentation with general variables without taking into consideration the subcultures & 0.05 & 3 & 0.08 \\
\hline T7-the competitor's progress in other developing countries & 0.04 & 4 & 0.16 \\
\hline T8-recission in America & 0.08 & 5 & 0.40 \\
\hline T9—demonetizing the tourist's demands with changing the tourist's imaginations from the adopted style & 0.02 & 4 & 0.08 \\
\hline T10—removing the small companies through big ones & 0.05 & 5 & 0.25 \\
\hline T11—using unfair competitive practices for damaging or destructing other firms & 0.02 & 4 & 0.16 \\
\hline Total & 1 & - & 3.43 \\
\hline
\end{tabular}

Source: [The analysis of research findings by authors, 2010]. 
Table 2. Results of internal factors analysis affecting marketing tourism of America.

\begin{tabular}{|c|c|c|c|}
\hline Internal environment (weaknesses and strengths) & weight & grade & Weighted score \\
\hline $\begin{array}{l}\text { S1—existing tourism markets with the highest compliance with } \\
\text { what are existed and tourism facilities }\end{array}$ & 0.07 & 4 & 0.28 \\
\hline $\begin{array}{l}\text { S2_-adapting the type of advertisements with the needs and demands of } \\
\text { actual and potential tourists }\end{array}$ & 0.03 & 4 & 0.12 \\
\hline S3 - estimating the possible demand in each sector of tourism markets & 0.03 & 3 & 0.09 \\
\hline S4—enough identification of the status quo of tourism markets & 0.02 & 3 & 0.06 \\
\hline S5-clarifying the customers in each sector of the tourism market & 0.05 & 2 & 0.10 \\
\hline S6-identifying the needs and demands of tourists & 0.04 & 1 & 0.04 \\
\hline $\begin{array}{l}\text { S7-coordination between demand and supply of products } \\
\text { and tourism services }\end{array}$ & 0.02 & 1 & 0.02 \\
\hline S8_-paying attention to new needs of tourists & 0.01 & 2 & 0.02 \\
\hline S9-evaluating the criteria of market segmentation & 0.04 & 1 & 0.04 \\
\hline S10-increased right of customer's choice & 0.03 & 2 & 0.06 \\
\hline S11—maximizing the tourist's consumption & 0.02 & 3 & 0.06 \\
\hline S12—existing various courses related to tourism and marketing & 0.03 & 1 & 0.03 \\
\hline S13—consecrating adequate funding to marketing programs & 0.08 & 5 & 0.40 \\
\hline S14—existing much research in the field of market and marketing studies & 0.02 & 4 & 0.08 \\
\hline S15-existing statistical bases and appropriate tourism information & 0.05 & 5 & 0.25 \\
\hline $\begin{array}{l}\text { S16-a complete and comprehensive information regarding attractions } \\
\text { and tourists locations }\end{array}$ & 0.04 & 4 & 0.16 \\
\hline S17—existing skillful personnel in marketing & 0.05 & 4 & 0.20 \\
\hline S18-existing tourism offices in other countries & 0.02 & 4 & 0.08 \\
\hline W1-increasing prices in some market segments & 0.04 & 4 & 0.16 \\
\hline W2-exaggeration in portraying the destination features & 0.02 & 4 & 0.08 \\
\hline W3-changing the structures of life cycle in America & 0.02 & 1 & 0.02 \\
\hline W4-much migrations to America & 0.02 & 1 & 0.02 \\
\hline W5-changing the population structure in America & 0.03 & 3 & 0.09 \\
\hline W6-misuse of state officials & 0.08 & 4 & 0.32 \\
\hline W7-high cost of over-distributing goods and services & 0.05 & 3 & 0.15 \\
\hline W8-high cost of advertisement & 0.05 & 4 & 0.20 \\
\hline W9-lack of attention to ethical issues in marketing & 0.04 & 4 & 0.16 \\
\hline Total & 1 & - & 3.34 \\
\hline
\end{tabular}

Source: [The analysis of research findings by authors, 2010]. 
Table 3. Results of the analysis of the internal factors affecting tourism marketing in Iran.

\begin{tabular}{|c|c|c|c|}
\hline Internal Environment (Weaknesses and Strengths) & Weight & Grading & Weighted score \\
\hline S1—existing tangible and intangible cultural and historical heritages & 0.07 & 4 & 0.28 \\
\hline S2—diversity of natural landscapes and diverse climatic conditions & 0.08 & 5 & $0.40 \mathrm{~S}$ \\
\hline S3-Iranian cities as the cheapest cities in the world & 0.04 & 4 & 0.16 \\
\hline S4—ethnic and subcultures diversity in Iran & 0.3 & 2 & 0.6 \\
\hline S5-Iran's geographic position in the Middle East and Central Asia & 0.09 & 3 & 0.27 \\
\hline S6-existing young forces in the country & 0.05 & 4 & 0.20 \\
\hline W1-lack or shortage of researcher in the field of tourist's behavioral patterns & 0.07 & 2 & 0.14 \\
\hline W2-lack of connection between science and practice of marketing & 0.08 & 2 & 0.16 \\
\hline W3-changes in the country's population structure & 0.04 & 1 & 0.04 \\
\hline W4-shortage of skillful personnel in the delivery of tourism products and services & 0.04 & 2 & 0.08 \\
\hline W5-lack of a complete and comprehensive regarding tourism attractions & 0.05 & 4 & 0.20 \\
\hline W6-lack of statistical base and appropriate information for the tourists & 0.07 & 4 & 0.28 \\
\hline W7-poor infrastructures and tourism facilities in Iran & 0.09 & 5 & 0.45 \\
\hline W8-lack of existing a management in each sector of tourisms system & 0.6 & 2 & 0.12 \\
\hline W9-lack of funding for market and marketing segmentation & 0.05 & 4 & 0.20 \\
\hline W10-lack of using technological tools in marketing & 0.05 & 3 & 0.15 \\
\hline W11-lack of coordination in some patterns of market segmentation in the domestic market of Iran & 0.3 & 4 & 0.12 \\
\hline W12-marketing research is time consuming & 0.01 & 2 & 0.02 \\
\hline Total & 1 & - & 3.13 \\
\hline
\end{tabular}

Source: [The analysis of research findings by authors, 2010].

Table 4. Results of analysis of external factors on tourism marketing in Iran.

\begin{tabular}{|c|c|c|c|}
\hline External Environment & Weight & Grading & Weighted score \\
\hline O1—predicting demand in various market assessments & 0.04 & 3 & 0.12 \\
\hline O2-identifying the goals and motivations of tourists in the form of behavioral patterns & 0.05 & 2 & 0.10 \\
\hline O3_being aware of potential tourists & 0.04 & 2 & 0.08 \\
\hline O4-identifying the expected level and beyond the expectations of tourists & 0.03 & 1 & 0.03 \\
\hline O5—understanding how to supply goods and services to different market segments & 0.03 & 3 & 0.09 \\
\hline O6-promoting the level of tourist's loyalty to the company's regarded products and services & 0.05 & 2 & 0.10 \\
\hline 07-existing the areas for the future development of tourism in Iran & 0.07 & 4 & 0.28 \\
\hline $\begin{array}{l}\text { O8-meeting the needs and demands of internal tourists to prevent from the } \\
\text { outgoing exchange from the country }\end{array}$ & 0.09 & 3 & 0.27 \\
\hline O9-identifying the needs and demands of tourists in domestic and foreign tourism markets & 0.04 & 4 & 0.16 \\
\hline O10_increased rights for tourists to have a choice & 0.05 & 2 & 0.10 \\
\hline O11—finding tourism markets with the highest compliance with tourism attractions and facilities & 0.06 & 4 & 0.24 \\
\hline O12_-job creation in tourism sector & 0.08 & 5 & 0.40 \\
\hline T1-the superficiality of some classification of behavioral patterns & 0.06 & 2 & 0.12 \\
\hline T2-lack of repeating surveys from tourists & 0.07 & 3 & 0.21 \\
\hline T3-distributing survey forms in an inappropriate time and place & 0.02 & 3 & 0.06 \\
\hline T4-lack of meeting tourist's needs and demands of one market sector in good atmosphere & 0.05 & 5 & 0.25 \\
\hline T5-poor research in tourism market and marketing & 0.08 & 4 & 0.32 \\
\hline T6-lack of appropriate tourist acceptance culture in the country & 0.04 & 4 & 0.16 \\
\hline T7-lack of coordination of tourism-related sectors & 0.05 & 2 & 0.10 \\
\hline Total & 1 & - & 3.3 \\
\hline
\end{tabular}

Source: [The analysis of research findings by authors, 2010]. 


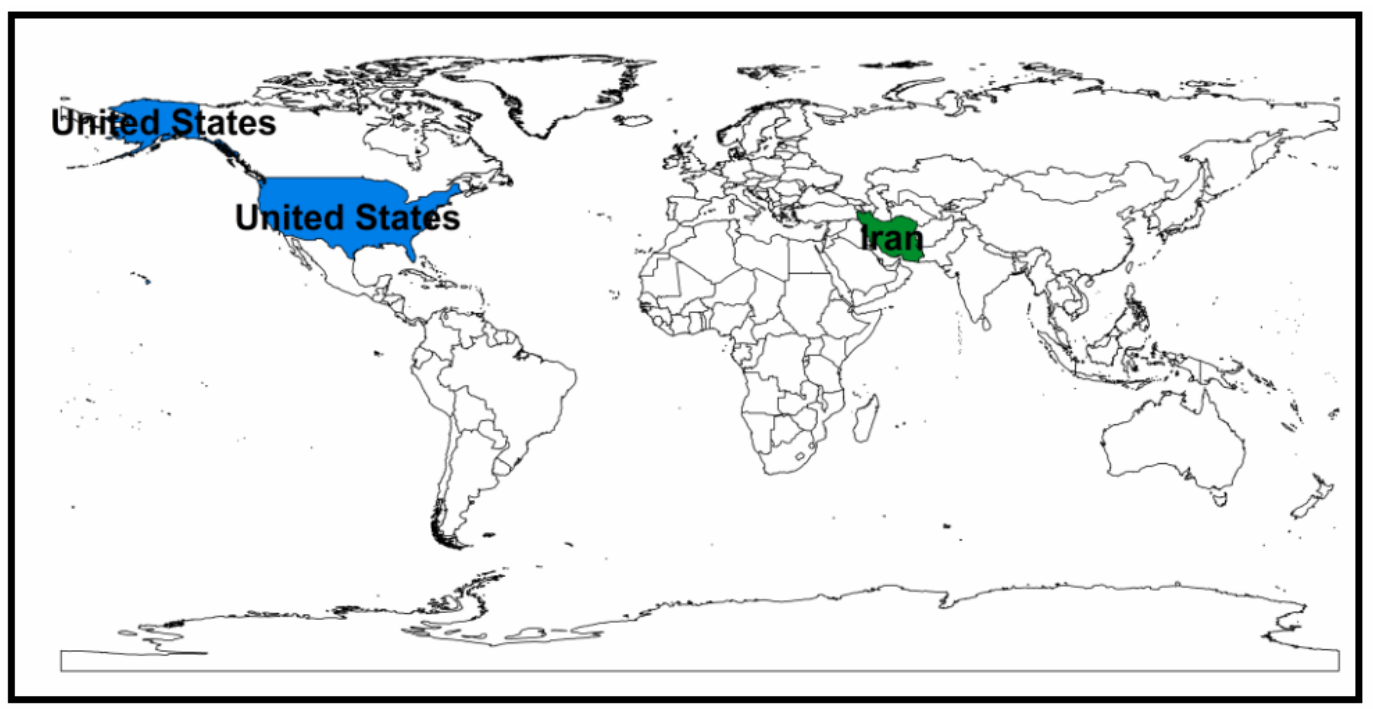

Figure 3. Iran and America location in world map (authors, 2010).

\section{Research Findings Analysis}

Today, the functions affecting Iranian and American tourist's behavioral patterns benefitted from SWOT analysis are considered as a new tool for performance analysis and functional gaps status will be used by strategic designers and evaluators. Therefore, this method is used in this study. In fact, this model is considered a conceptual framework for systemic analysis which makes possible the evaluation and comparison of bottle-necks, threats, harmful aspects, opportunities, demands and external environment conditions associated with strategic strengths and weaknesses (Table 5). The combination and incorporation of these factors with each other is in fact the base of devising four types of strategies, includeing 1) combining the strengths and opportunities (SO), 2) combining the strengths and threats (ST), 3) combining the weaknesses and opportunities (WO), 4) combining the weaknesses and threats (WT) [22].

\subsection{Analysis of Internal and External Factors Affecting Tourism Marketing Behavioral Patterns in AMERICA}

The results achieved from analyzing influential functions on tourism behavioral patterns in America, as noted in Table 1, indicate that the most important opportunities from the perspective of those polled (students of Tourism Industry Planning), include protection against competitors with a score of 0.35 , increasing foreign exchange earning with a score of 0.32 , tourism development as one of the factors of economic growth and the possibility of competitiveness in international tourism markets, each with a score of 0.20 . At the same time, of the most important threats are recession in America with a score of
0.40 , outfighting of small organizations through mammoth ones and preventing the entry of new companies with a score of 0.25 , using unfair competitive marketing practices for damaging or destruction of other companies and the progress of competitors in other developed countries, each with a score of 0.16 . The weighted score of external environment in marketing tourism of America is 3.43 which indicate its high influence.

Now, according to the results obtained in Table 2, the most important strengths from the perspective of those polled (students of tourism industry planning) include sufficient funding t marketing programs with a score of 0.35 , existing tourism markets with the highest compliance with what is owned and tourism facilities with a score of 0.28 , existing statistical bases and appropriate tourism information with a score of 0.25 , existing skillful personnel in marketing with a score of 0.20 . The most important weaknesses include misuse of state officials with a score of 0.32 , the high cost of advertising with a score of 0.20 , lack of attention to ethical issues in marketing and high prices in some market segments, each with a score of 0.16 . The weighted score in tourism marketing of America is 3.34 which indicate its high influence.

\section{Developing Affective Strategies on Tourist's Behavioral Patterns in Order to Optimize Marketing in America}

At this stage, interfering with any of the other factors and by analyzing how the strengths and weaknesses are influencing and being influenced from each other as well as threats and opportunities facing the tourism market in America, a final functional analysis is made by offering effective strategies on the tourist's behavioral patterns in 
Table 5. Quadruplet strategies of SWOT matrix and how to determine it.

\begin{tabular}{cll}
\cline { 1 - 2 } Weaknesses (W) (are listed) & \multicolumn{1}{c}{ Strengths (S) (are listed) } & \multicolumn{1}{c}{ Subjects } \\
\cline { 1 - 2 } Subjects & \multicolumn{1}{c}{ SWOT Matrix } \\
Opportunities (O) (are listed) & $\begin{array}{l}\text { SO strategies (max-max) } \\
\text { By making benefits of strengths, } \\
\text { the opportunities are utilized. }\end{array}$ & $\begin{array}{l}\text { WO strategies (min-max) } \\
\text { By making benefits of weaknesses, weaknesses are removed. }\end{array}$ \\
Threats (T) (are listed) & $\begin{array}{l}\text { ST strategies (max-min), } \\
\text { strengths are used to avoid threats. }\end{array}$ & $\begin{array}{l}\text { WT strategies (min-min), } \\
\text { weaknesses are reduced and threats are avoided. }\end{array}$ \\
\hline Subjects & &
\end{tabular}

Source: [22].

order to optimize the tourism marketing. In this way, these functions and its strategic planning are presented in the framework of four competitive basic strategy, namely competitive, diversity, defensive and revisionist strategies as follows:

Competitive strategies affecting tourist's behavioral patterns in America's marketing:

So1-designing conceptual diagrams: these diagrams are designed in two parts; in part one the expected level and beyond expectations in every part of the market are scored and in the second part, the tourists give scores to their satisfaction about facilities on their patterns which by comparing the two parts, the deficiencies are known in the part of tourism and some plans are devised to eliminate it;

So2-presenting behavioral patterns with new variables by the companies and organizations to find new markets;

So3-the participation of same level enterprises in order to take advantage of new opportunities; in this state, companies are able to reach their specific targets by combining capital, managerial capabilities and marketing resources;

So4-Finding the most appropriate media with regard to tourist's behavioral patterns; considering the fact that which media the parts of the market deals with, the media appropriate to that market can be selected for advertising;

So5-product development and tourism services with the current product development, services, creativity and innovation to create new products and services.

Diversity strategies (ST) affecting tourist's behavioral patterns in America marketing:

St1-focusing on submarkets in other countries;

St2-research regarding other countries' domestic markets;

St3 - changing the criteria and segmentation standards of the market according to new demands;

St4-developing ethical marketing policy; these policies should include measures of advertising, giving services to customers in diverse parts of the market, pricing and competitive ethical criteria;

St5-appointing prizes and supporting new ideas in the field of marketing and competition

Defensive strategies (WT) affecting tourist's behavioral patterns in America marketing:

Wt1-reviewin and assessing advertising and progressive tax on the cost of advertising;

Wt2-development of observer sector interfering with each factor on each other in the whole country's marketing system;

Wt3 - taking advantage of focused marketing; whenever the market is faced with restrictions, instead of trying to look for a small proportion of a great market, the company tries to create a relatively small portion of one or more submarkets.

Revisionist strategies (WO) affecting on tourist's behavioral patterns in America's marketing:

Wo1-redicing costs in order to fit the prices of goods and services in market sectors;

Wo2-reviewing the consumer's demands and tourism organizations needs and long-term interests of consumers.

\subsection{Analysis of Internal and External Factors Affecting the Behavioral Patterns of Tourism Marketing in Iran}

The results obtained from analyzing functions affecting the behavioral patterns of tourism marketing in Iran, as noted in Table 3, suggests that the most important strengths from the perspectives of those polled (students of tourism industry planning) include a variety of different landscapes and climatic conditions with a score of 0.40 , existing tangible and intangible historical and cultural heritages with a score of 0.28 and Iran's geographical position in the Middle East and Central Asia with a score of 0.27 ; meanwhile their most important weaknesses are infrastructures and tourism facilities weaknesses with a score of 0.45 , lack of statistical and information base for the tourists with a score of 0.28 and lack a complete and comprehensive information regarding 
tourism attractions with a score of 0.20 . The weighted score of internal environment in tourism marketing in Iran is 3.13 which indicate its high influence.

Now, according to the results obtained from Table 4, the most important opportunities from the perspectives of those polled (students of tourism industry planning) affecting tourism marketing is job creation in the field of tourism with score 0.40 , existing the field of future development of tourism in the area with the score 0.28 , satisfying the needs and demands of foreign tourists to avoid outgoing foreign exchange from the country with the score 0.27; in addition, the most important threats are weaknesses in market research and tourism marketing with the score 0.32 , lack of meeting the needs and demands of tourists of one market segment in an appropriate environment with the score 0.25 and superficiality of some behavioral patterns division with the score 0.12 .

The weighted score of external environment in Iran's tourism marketing is 3.3 which show its high effectiveness.

\section{Developing Strategies Affecting Tourist's Behavioral Patterns to Optimize Marketing in Iran's Tourism}

Now basic competitive, diversity, defensive and revisionist strategies and their functions and strategic planning in Iran is presented as follows:

Competitive strategies (SO) affecting tourist's behavioural patterns in Iran's marketing:

So1-analyzing the tourist's behavioral patterns in Middle East and Central Asia and Persian Gulf countries as targeted markets towards planning to achieve tourism markets appropriate to the country's tourism attractions;

So2-Organizing the tourism advertisement according to tourist's needs and demands and tourism destinations attractions;

So3-Creating advanced courses of management and tourism marketing for youths in order to utilize and employ a trained group in the positions related to marketing in the country and supporting new ideas in tourism marketing system.

Diversity strategies (ST) affecting tourist's behavioural patterns in Iran's marketing:

St1 - designing products and presenting services appropriate to tourist's needs and demands of different cities and ethnics;

St2 - using secondary data, including the ones other people and organizations or that organization itself have collected for other purposes such as sociological, psychological and geographical information which can be utilized in Iran's targeted tourism marketing.

Defensive strategies (WT) affecting tourist's behavioural pattern in Iran's marketing:

Wt1—selecting efficient managers for each segment of the market to establish intersection cooperation;

Wt2-using advertisement in math media to make publicize the tourism culture among people;

Wt3-constricting behavioral patterns with variables consistent with Iran's tourism marketing;

Wt4-designing new patterns with repeated surveys due to changes in variables such as changes in population structure of internal and external tourism markets;

Wt5-utilizing and employing tourism experts out of successful marketing companies in developed countries.

Revisionist strategies (WO) affecting tourist's behavioral patterns in Iran's marketing:

Wo1-application of copycat marketing and taking advantage of successful marketing patterns in developed countries appropriate to targeted markets in Iran's marketing;

Wo2-developing and designing local patterns appropriate to market variables to correctly segment the tourism market;

Wo3-participating of same level organizations for taking more advantage of new opportunities; in such case, the mentioned organizations can reach their goals with the combination of capital, managerial abilities and marketing resources.

\section{Conclusions}

Tourism markets can be flourished primarily through identifying behavioral patterns and attracts the potential tourists to purposes intended. On the other hand, the needs and demands of tourist can be identified well with a customer-focused marketing and marketers will be consciously make a plan for attracting tourists and therefore the level of tourist's satisfaction will be increased. Travelling repetition will be increased by increasing the level of satisfaction and demand will be maintained in a desirable level and hence tourists are indirectly involved in tourism planning.

Reviewing the analysis of the factors influencing tourist's behaviors in America's market division showed that tourism market in this country was vastly developed and marketing science is closely linked to marketing practice through supporting the valuable studies done in behavioral patterns and the external environment with the weighted score of 3.43 is more influencing than its internal environment with the weighted score of 3.34. However, the studies and researches in Islamic Republic of Iran associated with tourism marketing and the factors affecting tourist's behavioral patterns is in its starting point and then requires being supported and more publicly and personally financed. Nevertheless, the external environment with the weighted score of 3.3 is more effective than internal environment with the weighted score 
of 3.13 in this country. Now, a fundamental question is raised indicating that given the America's successes in tourism marketing and its difference with Iran, is America's strategies can be utilized for improving and promoting Iran's tourism marketing as well as the strategies recommended for Iran?

According to the studies performed by the writers in this regard, it can be said that America's tourism development strategies will be applied in Iran when it is put in the socio-cultural, economic and potential contexts of Iran's tourism; otherwise, this industry may be led to instability due to developing inappropriate tourism markets. In other words, application of copycat marketing and utilizing successful marketing patterns in developed countries according to Iran's targeted tourism markets will be effective by providing and developing indigenous patterns appropriate to Iran's market variables in order to properly exploit the tourism market.

\section{REFERENCES}

[1] S. Tayebi, R. Babaki and A. Jabari, "Study of the Relationship between Tourism Development and Economic Growth in Iran (1959-2004)," Bulletin of Humanities and Social Sciences Especially in Economics, Vol. 26, No. 7, 2007, pp. 83-110.

[2] N. Naserpour, "Studying and Explaining the Obstacles Facing Tourism Industry in Lorestan Province and Presenting Appropriate Strategies in this Regard,” MA Thesis, Mazandaran University, Babolsar, 2003.

[3] R. Heydari, "Principles of Tourism Industry Planning," SAMT Publications, Tehran, 2008.

[4] S. Amirtahmaseb, "The Typology of Inbound Tourists Visiting Iran,” Master Thesis, Department of Business Administration and Social Sciences, Division of Industrial Marketing and E-Commerce, Lulea University of Technology, Lulea, 2007.

[5] M. Yari, "Behavioral Patterns of Khoramabad Pre-Province Tourists," MA Thesis, University of Sistan and Baluchestan, Zahedan, 2011.

[6] H. Esmaelpour, "Principles of Marketing Management," Negah Danesh Publications, Tehran, 2005.

[7] R. Doswell, “Tourism Management,” Cultural Research Office Publications, Tehran, 2010.

[8] M. Ketabchi, "Principles of Marketing of Travel and Marketing Services,” Faras Publications, Tehran, 2004.
[9] M. Kazemi, “Analysis of Zahedan Citizen’s Perceptions in Chabahar Tourism Development," Journal of Geography and Development, Vol. 6, No. 12, 2006, pp. 81-100.

[10] K. Kamali and M. Dadkhah, "Networking and Network Management (Scientific-Practical)," Shahre Ashoub Publications, Tehran, 2005.

[11] K. G. Brown, "Island Tourism Marketing Music and Culture,” International Journal of Culture Tourism and Hospitality, Vol. 3, No. 1, 2009, pp. 25-32. doi:10.1108/17506180910940324

[12] P. Laimer and W. Juergen, "Portfolio Analysis as a Strategic Tool for Tourism Policy,” Tourism Review, Vol. 64, No. 1, 2009, pp. 17-31. doi:10.1108/16605370910948830

[13] O. C. Walker, J. Mullins and H. Boyd, "Marketing Strategy: A Decision Focused Approach,” 7th Edition, McGraw-Hill/Irwin, 2010.

[14] R. Lankovar, "Tourism Sociology and Travelling," Shahid Beheshti University, Tehran, 2002.

[15] L. Lumsdon, “Tourism Marketing," Thomson Business Press, London, 1997.

[16] B. Ranjbarian and M. Zahedi, "Study of the Effects of Repeating Traveling to Isfahan on Foreign Tourist's Satisfaction," Journal of Geography and Development, Vol. 9, No. 9, 2007, pp. 65-78.

[17] M. Kazemi, “Tourism Management,” SAMT Publications, Tehran, 2008.

[18] R. Jarvandi and N. Forghani, "Comparison of Travelling Motives Among Two Young and Elderly Generations (Case Study of Shiraz City Travellers),” Journal of Youth Studies, Culture and Society, 2nd Edition, Vol. 2, 2009, pp. 123-143.

[19] M. Alilou, S. H. Razmi and F. Nemati Sogoulitapeh, "Comparison of Group Personality Traits of Iranian Tourists with Non-Tourist Groups," Studies on Behavioral Sciences, Vol. 1, No. 7, 2009, pp. 55-62.

[20] I. Ebrahimzadeh and A. Aghasizadeh, "Analyzing the Factors Affecting Tourism Development in Chabahar Coastal Area, Using SWOT Strategic Model," Journal of Urban and Regional Researches and Studies, Vol. 1, No. 1, 2009, pp. 107-128.

[21] Research Unit and Cosmography Compilation, "Cosmography Comprehensive Atlas,” Gitashenasi Publications, Tehran, 2005.

[22] I. Ebrahimzadeh, "Land Preparation and Environmental Planning in South East of Iran,” Etelaat Publications, Tehran, 2010. 